\title{
ANÁLISE DE POLÍTICAS PÚBLICAS PARA DOAÇÃO DE ÓRGÃOS HUMANOS PARA TRANSPLANTE: UMA FORMA DE INCREMENTAR O DIREITO CONSTITUCIONAL À SAÚDE NO BRASIL ${ }^{1}$
}

\section{PUBLIC POLICY ANALYSIS FOR DONATION OF HUMAN ORGANS FOR TRANSPLANTATION: A WAY TO INCREASE THE CONSTITUTIONAL RIGHT TO HEALTH IN BRAZIL}

\section{SÁVIO DE BRITO FONTENELE}

Doutorado (2015) e mestrado (2010) em Engenharia Agrícola. Graduado em Engenharia de Produção Mecânica pela Universidade Regional do Cariri (2006). Área de concentração: manejo e conservação de água e solo no semiárido, pela Universidade Federal do Ceará - UFC. Atualmente é docente da Faculdade Paraíso do Ceará.

\section{ROBERTA MARINA CIOATTO}

Doutoranda em Direito pela Universidade Federal de Santa Catarina (UFSC). Mestre em Direito com ênfase em Direitos Sociais e Políticas Públicas de Inclusão Social pela Universidade de Santa Cruz do Sul (Unisc/Brasil) e Mestre em Direito das Autarquias Locais pela Universidade do Minho (Uminho/Portugal).

\footnotetext{
${ }^{1}$ Este artigo foi desenvolvido a partir de discussões do Grupo de Estudos e Pesquisas Acesso à Justiça e Políticas Públicas, do qual os autores fazem parte. Projeto: Bioética, Direito e Políticas Públicas. Os autores participaram igualmente de todas as etapas da elaboração do texto, sendo que o trato estatístico é de contribuição exclusiva do doutor do trabalho enquanto que é de exclusividade da mestre a busca por informações sobre doações e transplantes nos países estudados.
} 


\section{RESUMO}

Objetivo: $O$ presente trabalho tem como objetivo analisar uma série temporal de transplantes de órgãos humanos em diversos Estados e quais as políticas públicas adotadas para elevação e/ou manutenção do número de transplantes.

Metodologia: Para tanto, tratou-se estatisticamente um conjunto de dados disponibilizado pelo Global Observatory on Donation and Transplantation e, após essa análise, abordou-se as informações por meio de uma revisão bibliográfica. É uma pesquisa descritiva e aplicada.

Resultados: Nos doze Estados que geram, formalmente, os melhores índices em números absolutos de transplantação, algumas políticas mostram-se importantes, como a adoção do sistema presumido de doação, a qualificação e o treinamento das equipes e também a doação após a morte cardiocirculatória.

Contribuições: Os doadores efetivos de órgãos para transplantação estão muito aquém dos doadores em potencial. Essa escassez estimula os incessantes esforços para suprir a demanda, sendo preciso o impulsionamento de políticas públicas a fim de atender o maior número possível de enfermos. Claramente, há uma forte necessidade de inovadoras abordagens para o problema; desafios substanciais permanecem para que esses brasileiros tenham seu direito constitucional à saúde garantido.

Palavras-chave: Doação de órgãos; transplante de órgãos; políticas públicas; direito à saúde; bioética.

\section{ABSTRACT}

Objective: To analyze a time series of human organ transplants in several States and what public policies have been adopted to increase and/or maintain the number of transplants.

Methodology: A set of data provided by the Global Observatory on Donation and Transplantation was statistically treated and, after this analysis, the information was approached through a bibliographic review. It is a descriptive and applied research.

Results: In the twelve States that formally generate the best transplantation rates in absolute numbers, some policies are important such as the adoption of the presumed donation system, the qualification and training of the teams and also the donation after cardio-circulatory death. 
Contributions: Effective organ donors for transplantation fall far short of potential donors. This shortage stimulates the ceaseless efforts to supply the demand, being necessary to promote public policies to attend the greatest possible number of patients. Clearly, there is a strong need for innovative approaches to the problem; substantial challenges remain for these Brazilians to have their constitutional right to health guaranteed.

Keywords: Organ donation; organ transplantation; public policy; right to health; bioethics.

\section{INTRODUÇÃO}

Os órgãos humanos para transplante somente podem ser extraídos, de pessoa falecida, após o diagnóstico de morte encefálica, cujas causas mais comuns são: traumatismo cranioencefálico e acidente vascular encefálico. Fato que se apresenta como uma restrição para as potenciais doações e a execução do processo de transplantação de órgãos, uma vez que isso só ocorre em uma porção ínfima de mortes. Desse modo, mesmo que cada pessoa concordasse em doar órgãos quando de sua morte, ainda assim haveria um déficit de órgãos. Vale salientar que, alguns países como os Estados Unidos da América conseguiram uma elevação em seus números de doações e transplantes após considerarem também o critério de morte cardiocirculatória.

Ademais, os doadores efetivos estão muito aquém dos doadores em potencial, e a estimativa da Organização Mundial da Saúde - OMS é que o transplante de órgãos cubra apenas $10 \%$ da necessidade global. Assim, o tempo de espera é longo e, com o aumento da expectativa de vida, há uma demanda maior por doadores de órgãos, pois o transplante é a melhor - senão a única - solução para o paciente na quase totalidade dos casos. Essa escassez estimula os incessantes esforços para suprir a demanda, sendo preciso o impulsionamento de políticas públicas a fim de atender o maior número possível de enfermos e garantir, assim, o direito constitucional à saúde.

A Organização Mundial da Saúde, em sua Resolução WHA 63.22 de 2010, descreve onze princípios que estabelecem a natureza voluntária e não monetária da 
doação de órgãos para transplante. Com isso, as políticas públicas definidas pelos diversos países que mostram sensibilidade para com o tema tratam a doação como algo não mercantilizado.

No Brasil, a Constituição Federal, em seu artigo 199, § $4^{\circ}$, quando trata "da saúde", diz que lei disporá sobre condições e requisitos que facilitem a remoção de órgãos humanos para fins de transplante, sendo vedado todo o tipo de comercialização.

Políticas como a presunção da doação (sistema opt out), qualificação e treinamento das equipes que lidam com os familiares nesses momentos difíceis, redução do descarte, reformulação das prioridades das listas, compensação de doadores e redução das exigências já são trabalhadas em alguns países e mostram perspectivas favoráveis a médio e longo prazo.

Diante dessa problemática, o objetivo deste estudo é analisar uma série temporal de transplantes em diversos países, para verificar o número de transplantes por ano, em valores absolutos, e quais as políticas públicas adotadas para elevação e/ou manutenção do número de transplantes em territórios nacionais.

\section{MÉTODOS}

O estudo proposto foi desenvolvido utilizando os dados de uma série temporal de sete anos. Esse conjunto de elementos foi tratado estatisticamente usando o Microsoft Excel®. Nesse tratamento, foram selecionados os doze países com o maior número de transplantes dentro do intervalo de anos disponível (2010-2016). Depois dessa filtragem, os dados foram apresentados em gráfico de série temporal e foram calculadas as taxas de ascensão, recessão ou estagnação dos números absolutos de transplantes entre os anos da série, observando-se as maiores e menores taxas.

Após a conclusão da análise de dados, uma densa busca por informações sobre doações e transplantes nesses países foi realizada no intuito de entender os motivos das ascensões, das recessões ou das estagnações que vieram a ocorrer 
durante o período analisado. Para isso, utilizou-se em maior volume notícias veiculadas na imprensa estrangeira, que publica fatos atuais com maior velocidade do que os periódicos científicos.

No tocante aos fins, a pesquisa em questão trata-se de uma pesquisa descritiva, a qual está relacionada à "descrição do objeto por meio da observação e do levantamento de dados ou ainda pela pesquisa bibliográfica documental (Barros; Lehfeld, 1990). No caso, a investigação usa um conjunto de dados secundário, gerado e disponibilizado pelo Global Observatory on Donation and Transplantation - GODT (Observatório Global de Doações e Transplantes), tentando traçar um perfil de cada país no tocante ao tema, relacionando os números à condição do sistema de doações e transplantes e às políticas adotadas pela nação em estudo. Além disso, essa pesquisa ainda pode ser considerada aplicada, pois a mesma visa contribuir para a definição das melhores políticas públicas a serem utilizadas para ascender os números relativos a doações e transplantes no globo.

\section{ANÁLISE DE POLÍTICAS PÚBLICAS PARA DOAÇÃO DE ÓRGÃOS HUMANOS PARA TRANSPLANTE}

A Figura 1 mostra os números dos 12 principais países que possuem um sistema de doação e transplante de órgãos e geram, formalmente, os melhores índices mundiais, em números absolutos, entre o período de 2010 a 2016.

Os Estados Unidos da América são o principal país na realização de transplantes. Desde 2010, os números crescem a cada ano com taxa média de ascendência em torno de $4 \%$ (Figura 1). Contudo, em 2012, houve um decaimento de aproximadamente 1,6\%. Em 2016, uma elevação brusca da ascendência (por volta de 8,0\%) pôde ser percebido, observando a mudança de angulação da curva no gráfico da Figura 1. Essa ascendência no período final leva ao mais alto nível de transplante em valores absolutos. Ademais, salienta-se que desses números elevados apresentados pelos EUA, $14,5 \%$ dos doadores são oriundos de morte circulatória. 
Tipo de procedimento utilizado por demais países, como Reino Unido $(40,4 \%)$ e Espanha (12,6\%) e observado em pequenas porcentagens em países como França (3,5\%), e Itália $(0,5 \%)$.

Inobstante os Estados Unidos estarem no topo da lista de transplantes de órgãos realizados e terem aumentado em mais de $20 \%$ o número de procedimentos concretizados no período analisado, quase 120.000 pessoas permanecem em listas de espera no país. Destas, aproximadamente 8.000 não viverão para receber o órgão, uma média de 20 pessoas falecidas por dia na espera por um transplante (OSSOLA, 2017).

FIGURA 1 - Os 12 principais países em números absolutos de transplantes entre 2010 e 2016.

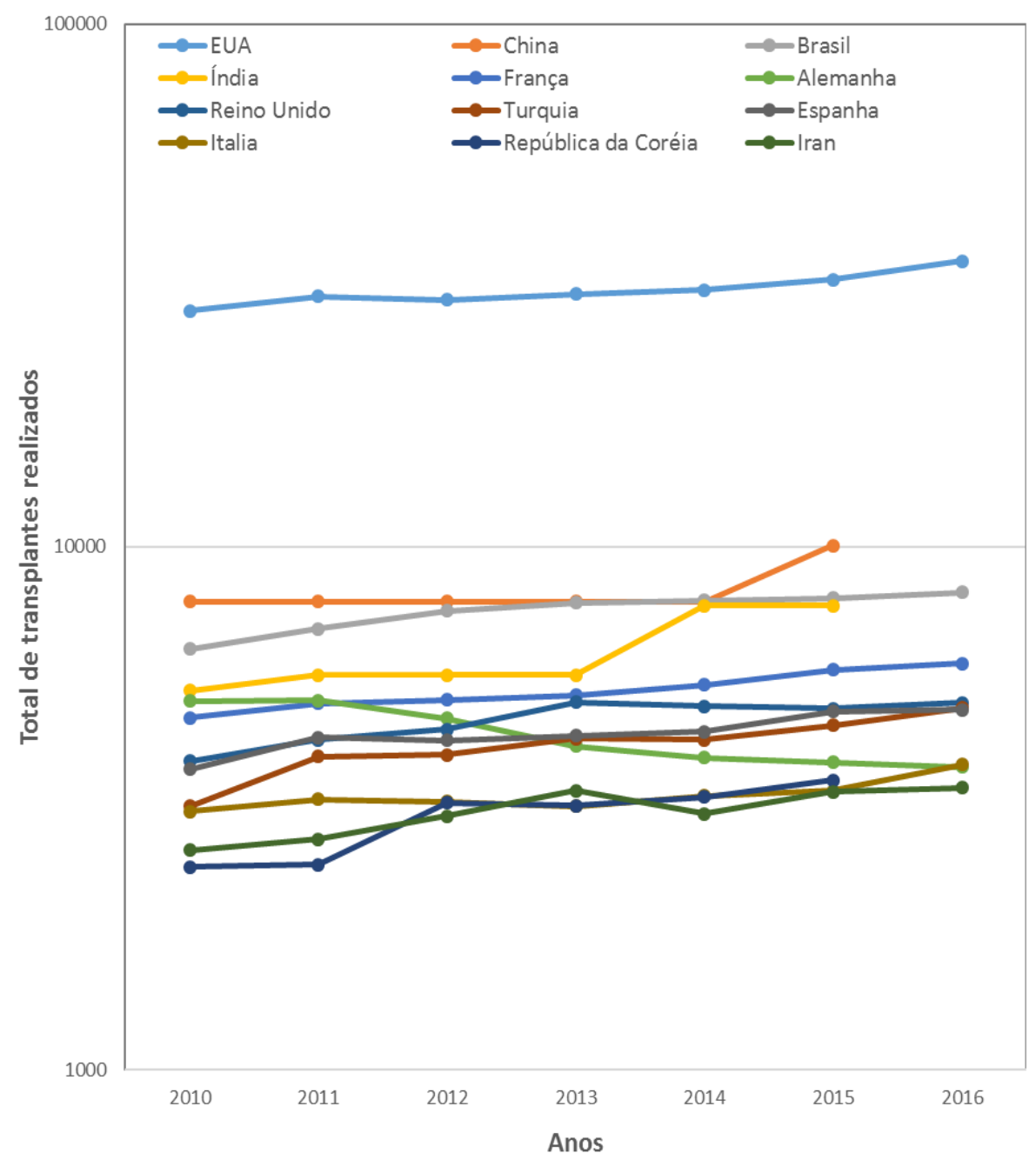


A China foi o segundo país no ranking de transplantes entre 2010 e 2013. Porém, o número total de transplantes permaneceu estagnado em 7.864 casos entre 2010 e 2014 (Figura 1). Cerca de 300.000 pacientes necessitavam com urgência de um transplante em 2014, sendo que apenas 10.000 operações eram realizadas anualmente (CHINA, 2014). De 2014 para 2015, o número de transplantes ascendeu em aproximadamente $22 \%$, tornando a China novamente o segundo país com mais transplantes. Não há informações para o ano de 2016.

Apesar de se posicionar bem no ranking de números absolutos, a China, por ter a maior população do planeta, possui indicadores negativamente discrepantes quando a análise é feita em números per capita. No país, menos de $1 \%$ da população que necessita de um transplante o recebe, em comparação com cerca de $20 \%$ nos Estados Unidos. Os costumes chineses sugerem que os corpos sejam enterrados ou cremados intactos para que uma pessoa possa reencarnar inteiramente. Isso desencorajaria os cidadãos a doar seus órgãos e representaria a principal razão de o país ter uma das mais baixas taxas de doação. A falta de transparência nas atividades médicas e no sistema de doação e transplantes seriam outros fatores a justificar os insignificantes números de doações voluntárias (FAN, 2014).

A China proibiu o comércio de órgãos humanos em 2007 e, em 2009, condenou traficantes à pena de morte. Um fator discutível é que $90 \%$ dos suprimentos de órgãos no país viriam de prisioneiros executados (FAN, 2014). "Os regulamentos permitem o uso de órgãos retirados de executados em três situações: no caso de um condenado sem parentes; se os prisioneiros se voluntariam para ser doadores; e, se a família da pessoa executada fornecer seu consentimento" (YANG, 2012, online). Mas há muito acusam o governo de tomar órgãos de detentos sem consentimento, ou com prisioneiros pressionados a doar (CHINA, 2014). Se não bastasse, outra situação é levantada. Em 2011, a pena de morte era administrada por projétil de arma de fogo. Em 2012, a injeção letal teria passado a ser a prática, o que facilitaria a recuperação e o aproveitamento de órgãos. Durante muito tempo, as autoridades chinesas recusaram-se a reconhecer internacionalmente a utilização de órgãos de prisioneiros 
para transplantes (FAN, 2014), mas o teriam feito em 2005 e a colheita teria sido encerrada em 2014 (VATICAN CONFERENCE, 2017).

O Brasil é o terceiro país que mais faz transplantes no mundo. ${ }^{2}$ Desde 2010 , os números crescem com taxa média de $4,3 \%$ ao ano. No entanto, ao longo do período em análise, houve um decaimento na taxa de transplantes, de 9\% de 2010 para 2011 a 2\% de 2015 para 2016, com mínimos (1\%) ocorrendo de 2013 para 2014 e de 2014 para 2015 (Figura 1). Em 2016, a média de doadores efetivos de órgãos por milhão de população (pmp) no Brasil foi 14,6, enquanto que Espanha e EUA ostentaram 43,4 e 31,0, respectivamente. ${ }^{3}$ Inobstante, o índice brasileiro ultrapassou consideravelmente os 9,9 de 2010. Em 2017, 1.689 brasileiros faleceram em lista de espera e 2.740 doações deixaram de ser concretizadas diante da recusa expressada pelos familiares do potencial doador, não superando os 16,6 doadores efetivos por milhão de população. Santa Catarina e Paraná são os estados brasileiros que ultrapassaram os 30 doadores pmp, com 40,8 e 38,0, superando Estados Unidos e se aproximando da melhor taxa mundial, da Espanha (RTB, 2017).

A Índia está em quarto lugar no ranking dos países que fazem transplantes. Entre 2010 e 2013, fez em média 5.588 transplantes por ano. Em 2014, houve um acréscimo de $36 \%$ no número absoluto de transplantes nesse país (Figura 1 ). Esse valor mantém-se constante para o ano de 2015. Para 2016 não há dados para a Índia. Vale salientar que com o acréscimo de transplantes em 2015, a Índia aproxima-se bastante do Brasil. Em 2013, a diferença entre esses países era de aproximadamente 2.150 transplantes. Para 2014, essa diferença caiu para 180 casos.

$\mathrm{Na}$ Índia, a venda de um rim como chance de escapar da pobreza ter-se-ia espalhado pelas cidades. No mercado negro, o órgão teria sido negociado por 55.000 rúpias ou 800 euros, o que pode representar bastante dinheiro para muitos indianos. O país elevou a pena para o comércio de órgãos humanos de dois para cinco anos

\footnotetext{
${ }^{2}$ Se considerada a China. Ocorre que, tendo em vista sua alegada principal fonte de obtenção de órgãos, os dados chineses são, por muitos, desconsiderados. Inclusive, artigos acadêmicos chineses sobre transplantes não seriam recebidos por revistas científicas internacionais para publicações por esta razão.

3 Dados de 2016 para alguns outros países: França 28,7; Itália 24,3; Reino Unido 21,4; Holanda 14,7; Coreia do Sul 11,4; Alemanha 10,4; Irã 10,9; Turquia 7,1 (RTB, 2017).
} 
de prisão, mas as transações não diminuíram. "O risco de ser pego também não é grande, ainda mais porque o doador tem apenas que se apresentar como amigo do receptor e declarar o dinheiro pago pelo órgão como um presente" (KIDNEYS, 2012, online). Desde 1987, médicos indianos defendem a compra e venda de rins entre pessoas vivas e sem grau de parentesco (GARRAFA, 1993).

Alemanha, quinta colocada do ranking de transplantes em números absolutos, vem reduzindo seus números de transplantes, com taxa média de $-4 \%$ ao ano. Durante o período analisado (2010 a 2016), a Alemanha cai da quinta para a décima colocação (Figura 1). A taxa máxima de decréscimo dos números de transplantes no ano é de $-11 \%$ entre 2012 e 2013. Em todo o período analisado, o país reduziu a realização de mais de 1200 transplantes por ano.

Em 2017, menos de 800 pessoas foram doadoras no país. Um total de 2594 órgãos foram doados, dos quais mais de 200 vieram do exterior. Atualmente, cerca de 10 mil pessoas estão à espera de um órgão no país e, em média, três pessoas na lista de espera morrem todos os dias (WER NICHT, 2018).

O país teve uma contínua queda no número de doações depois da revelação de fraudes no sistema em 2012 (DIE AUFARBEITUNG, 2016; BERNDT, 2016b) mesmo ano em que alterações legislativas foram produzidas no intuito de aumentar o número de doadores (NEW DUTCH, 2018). Desde a descoberta de manipulações, os centros de transplante são continuamente revisados por uma comissão independente no intuito de evitar futuros casos e restaurar a confiança nas clínicas; mesmo assim, mantém-se o declínio (SELBSTANZEIGE, 2014). A corrupção ou a ganância, mas também a pressão da competição entre os centros de transplante teria favorecido as adulterações (ÄRZTE, 2014). Presume-se que para melhorar as chances de sobrevivência de seus pacientes e para garantir cirurgias lucrativas para o hospital em que trabalhavam, cirurgiões teriam manipulado os resultados laboratoriais de pacientes para que estes fossem antecipados nas listas de espera (GINZEL, 2012). De 2010 a 2012, pacientes podem ter recebido transplantes sem efetivamente terem direito. Existem alegações de que seus dados tenham sido manipulados de modo que parecessem estar mais doentes, falsificando-se a urgência; ou que altas doses de 
medicamentos ter-Ihes-iam sido ministradas de modo a agravar seu estado de saúde para conseguirem o órgão rapidamente (BARTENS, 2014; BERLIN DOCTOR, 2014; BERNDT, 2016a; BERNDT, 2016b; BERNDT, 2015; BERNDT, 2017).

Na clínica universitária em Regensburg, um médico teria falsificado os dados relativos a mais de 20 de seus pacientes entre 2004 e 2006, a fim de beneficiá-los na lista de espera por um transplante de fígado. Ele também é acusado de ter quebrado as regras em 2005, colocando pacientes jordanianos na lista de espera dos pacientes europeus. Isso, na época, teria sido classificado como infração administrativa. Em 2008, atuando na clínica universitária de Göttingen, ele teria falsificado dados para outros tantos pacientes (NEW DUTCH, 2018; ORGAN SCANDAL, 2012; KIDNEYS, 2012). Foi acusado criminalmente por ter falsificado documentos médicos para acelerar o processo de recebimento de fígado para seus pacientes em detrimento de outras pessoas que precisavam dos transplantes com mais urgência e que, diante do ocorrido, podem ter falecido (BGH 2017; ORGAN SCANDAL 2012). "O médico foi absolvido em 2015 depois que o juiz decidiu que não poderia ser provado exatamente quem havia morrido como resultado. Posteriormente, tornou-se evidente que a prática era muito mais difundida do que se pensava inicialmente." (NEW DUTCH, 2018, online, tradução nossa). 5 "Não se pode supor que o médico aceitou a morte de outros manipulando os dados de seus pacientes". Um comportamento moralmente repreensível, mas não punível - afirmou-se. Foram violadas diretrizes da Associação Médica Alemã, as quais, entretanto, por terem sido declaradas inconstitucionais, ${ }^{6}$ não

\footnotetext{
${ }^{4}$ A facilidade de manipulação de dados para este tipo de procedimento foi explicada pelo fato que um único médico fornecia os resultados de alguns exames laboratoriais para fins de registro, contrariamente aos casos de transplante de coração, por exemplo, cuja necessidade de transplante era estudada por pelo menos quatro médicos.

$5 \mathrm{Na}$ Alemanha, todos os resultados médicos são agrupados e enviados para a Fundação Eurotransplant, na Holanda, que é responsável pela lista de espera - e segue a ordem de urgência. A Eurotransplant é o escritório central para Alemanha, Holanda, Bélgica, Luxemburgo, Áustria, Eslovênia e Croácia. O sistema destina-se a garantir que os médicos não tenham influência sobre o recebimento. 6 Sobre a inconstitucionalidade do sistema alemão de transplantes: $<$ http://www.sueddeutsche.de/gesundheit/transplantationsmedizin-organspende-wird-fall-fuerbundesgerichte-1.2642384> e <http://www.sueddeutsche.de/gesundheit/transplantationsdrama-vatermutter-verzweiflung-1.2089718>.
} 
teriam sido aplicadas (BGH, 2017). Outros casos continuam sendo levantados (BERNDT, 2016b; BERNDT, 2017).

Essas ocorrências, e muitos outros fatores, podem ter baixado a já reduzida taxa de doação alemã (BERNDT, 2016b; DIE AUFARBEITUNG, 2016). Em 2017, o número de doadores de órgãos na Alemanha atingiu a maior baixa de todos os tempos (9,3 por milhão de população) e os pacientes no país estão cada vez mais dependentes de um programa europeu de intercâmbio de órgãos transfronteiriço; "como nos anos anteriores, hospitais alemães receberam corações, fígados e rins da Eurotransplant - cerca de 200 órgãos da Bélgica, Holanda, Croácia, Hungria, Áustria e Eslovênia chegaram à Alemanha por meio da rede" (GERMAN, 2018, online, tradução nossa).

Embora o número de doadores potenciais alemães esteja caindo drasticamente, cada vez mais croatas estão dispostos a doar, e a Alemanha colhe os benefícios da mudança de hábitos desses, que têm mais de 30 doadores por milhão de população. ${ }^{7}$ Os croatas fazem do país um dos mais bem-sucedidos dos oito membros da Fundação Eurotransplant, que aloca órgãos doados. Em 2017, 132 doadores tiveram os órgãos removidos na Croácia (GERMAN, 2018). No país, os gerentes de transplantes, as figuras-chave do sistema, são todos médicos que trabalham em hospitais, localmente, identificando e registrando potenciais doadores, treinando funcionários e fornecendo apoio aos parentes. O periódico Deutsche Welle apresenta um depoimento de Yasmin Redjepagic a respeito do sentimento dela e de sua família sobre transplante de órgãos. Enquanto estava de luto pela repentina morte de seu genitor:

Ela recebeu um telefonema do hospital em Zagreb, onde seu pai havia sido tratado. Os médicos perguntaram se poderiam remover órgãos saudáveis do falecido. O pai de Yasmin foi registrado como um doador de órgãos em potencial. A família pediu algum tempo para pensar sobre isso e pouco depois consentiram. "Nossos pais sempre pensaram que era melhor salvar as vidas de outras pessoas do que deixar os órgãos serem desperdiçados", disse

\footnotetext{
${ }^{7}$ O programa de doadores de órgãos da Croácia baseia-se num acordo de exclusão. Isso significa que cada cidadão torna-se um potencial doador de órgãos se não tiver explicitamente declarado sua recusa em fazê-lo antes de morrer. É o sistema opt out.
} 


\begin{abstract}
Yasmin. "Todos os membros da nossa família são potenciais doadores de órgãos. Falamos sobre isso com frequência". [...] "Doar um órgão é uma ação humana e digna", disse Yasmin. "No entanto, não podemos esquecer que envolve uma tragédia, a morte de um membro da família. Não é apenas um processo burocrático, mas também uma questão profundamente moral. As pessoas precisam do apoio e da empatia dos profissionais médicos. É isso que nos ajudou nessas circunstâncias dolorosas". Os órgãos do pai foram removidos no meio da noite. O médico encarregado do procedimento ligou na manhã seguinte para agradecer à família e dizer-lhes que estava acabado. "Esse gesto nos emocionou profundamente", disse Yasmin. "Depois do choque e da tristeza sem fim pela perda prematura de meu pai, senti que tínhamos feito algo bom. Uma vida chegou ao fim e ajudou a salvar outra". (GERMAN, 2018, online, tradução nossa).
\end{abstract}

Ocorre que a Eurotransplant inclui apenas países onde o sistema alcança no mínimo cerca de 10 doadores por milhão de população; e a Alemanha pode ficar aquém deste número. Sem o subsídio desta organização, haveria ainda menos órgãos, sendo que o país se beneficiou por anos da maior disposição para doar nos outros países (BERNDT, 2017).

As poucas doações poderiam ser, e muitas vezes são, justificadas pelo abalo na credibilidade da população na medicina de transplante. Entretanto, embora indiquem que as manipulações de dados de pacientes inicialmente abalaram sua confiança, doadores não teriam mudado de opinião, nem as clínicas estariam recebendo mais negações do que antes. "O declínio no número de doadores começou em 2010, bem à frente do escândalo. Naquela época 100 doadores de órgãos por mês eram a regra, agora são 60" (BERNDT, 2017, online, tradução nossa). Como causas, aponta-se o não comprometimento pessoal dos funcionários nas clínicas de coleta, que exige uma disponibilidade muito maior. Os médicos também estariam desmotivados diante das poucas sanções contra os médicos fraudulentos. Existem ainda os custos hospitalares: é "mais fácil e mais barato chamar um agente funerário e reciclar um leito de doença do que mantê-lo para o doador de órgãos e os diagnósticos necessários para a morte encefálica; e, posteriormente, a ocupação de uma sala de cirurgia para remoção de órgãos". "Por todo o esforço, as clínicas recebem montantes fixos relativamente apertados" (BERNDT, 2017, online, tradução nossa). Preocupa, ainda, o fato de que $90 \%$ dos médicos e enfermeiros alemães declararam não estar bem informados sobre questões de doação de órgãos, 
especialmente no que diz respeito a cuidar de parentes (ÄRZTE, 2014). Outrossim, o critério de morte encefálica enfrenta opositores. ${ }^{8}$ Mais "transparência e discussão pública são necessárias para uma maior confiança na medicina de transplantes" (BOYTCHEV, 2015, online, tradução nossa).

Os alemães têm outras alegações: disseram que não querem tomar uma decisão agora sobre doar órgãos; não querem lidar com assuntos relacionados à morte; e estão preocupados que, se concordarem em doar, e então ficarem gravemente doentes, os médicos não farão tudo o que puderem para salvá-los (WIDMAN, 2012).

$\mathrm{Na}$ França, sexta colocada no ranking dos transplantes, a média para o período de 2010 a 2016 é de 5.327 transplantes. Esse valor é representativo para o período, pois as variações foram mínimas (Figura 1). A taxa média de ascensão anual é 4\%, com máximas de 7\% (2010 a 2011 e 2014 a 2015) e mínimas de 2\% (2011 a 2012 e 2012 a 2013). Assim, os transplantes no país permaneceram no mesmo patamar durante todo o período analisado, com uma elevação de 1.264 procedimentos.

Desde 2000, o número de doadores de órgãos quase dobrou na França, mas esse aumento continua insuficiente. Os pacientes também dobraram no mesmo período devido ao envelhecimento da população. Em 2015, 571 pessoas escolheram doar enquanto vivos, 21.000 esperaram por um transplante e 553 morreram enquanto estavam na lista de espera por um órgão. O governo objetiva mudar esses números com uma lei em vigor a partir de $1^{\circ}$ de janeiro de 2017 (A PARTIR DU, 2016) regulando o princípio do consentimento presumido (BENJAMIN, 2016). Este princípio, que existe desde a Lei Cavaillet de 1976, presume que todos os adultos franceses consentem na remoção de seus órgãos após a morte, a menos que durante sua vida tenham expressado uma recusa. Como consequência, se o parente falecido não tomou as

\footnotetext{
${ }^{8}$ O diagnóstico de morte encefálica estabelecido pelo Comitê de Harvard em 1968 foi mundialmente aceito. Ocorre que se trata de uma "ficção médica e jurídica". O paciente declarado com morte cerebral permanece conectado a aparelhos de suporte vital - corado e com o coração batendo - para fins de preservação dos órgãos. Sua aparência "de vivo" dificulta a aceitação da morte pelos familiares, que se opõem à retirada.
} 
medidas oficiais para registrar sua recusa, a manifestação da família continua sendo importante. Uma pessoa poderá expressar sua recusa por meio de três possibilidades. Inicialmente, cadastro no Registro Nacional de Recusa, um formulário diretamente na Internet. Em seguida, um documento assinado e datado atestando a oposição à doação entregue a um parente. Finalmente, informar oralmente um ente querido sobre a oposição. Com a morte da pessoa, durante a entrevista com a equipe médica, este membro da família ou equipe de coleta do hospital terá que transcrever esta recusa por escrito, mencionando precisamente o contexto e as circunstâncias de sua expressão. A remoção de órgãos não será automática após a morte; acontece a partir do momento em que não houver recusa claramente expressada. Trata-se de uma possibilidade, de modo algum uma obrigação. Qualquer decisão a ser tomada deve levar em conta o contexto familiar. Acredita-se que o sucesso baseie-se em "melhor informação e conscientização pública e, especialmente, na qualidade do treinamento de profissionais de saúde que entrevistam famílias após a morte de um ente querido." "A taxa de recusa diminuirá, portanto, se, paralelamente à evolução da legislação, forem feitos esforços para informar e treinar os profissionais de saúde." Este decreto, que regula mais estritamente o princípio do consentimento presumido, visa, portanto, reduzir o número de recusas (BENJAMIN, 2016, online, tradução nossa).

O Reino Unido insere-se nessa lista como sétimo colocado. Com uma rápida ascensão nos primeiros anos, média de $9 \%$ de elevação no número de transplantes entre 2010 e 2013, o Reino Unido ultrapassa a Alemanha, que nesse período vem em queda, e chega muito próximo dos números franceses, que se mantinham praticamente estagnados no referido período (Figura 1). Contudo, entre 2014 e 2015, o Reino Unido passa por uma redução em seu número de transplantes, recuperando o patamar alcançado em 2013 apenas em 2016, com mais de 5.000 transplantes realizados.

A Espanha aparece nessa lista como oitava colocada, com valores absolutos de transplantes muito próximos dos do Reino Unido. O que ocorre ao longo do período estudado é que o Reino Unido chega a patamares mais elevados 3 anos antes que a Espanha, que só consegue elevar consideravelmente o número de transplantes a 
partir de 2014. A taxa média de ascendência dos números espanhóis é de 5\%, sendo que há um pico de evolução entre 2010 e 2011 (15\%) e um segundo momento com ascendência elevada, entre 2014 e 2015 (9\%). No restante dos anos houve uma evolução muito discreta, entre 1\% e 2\% (Figura 1).

De qualquer forma, é a Espanha que ostenta, há 26 anos, o recorde mundial de doadores de órgãos falecidos por milhão de habitantes: 43,4 em 2016 (ESPANHA É, 2017) e 46,9 em 2017 (EL ÉXITO, 2018).

O sistema espanhol é referência mundial. Conhece-se internacionalmente como Modelo Español ou Spanish Model o conjunto de medidas adotadas para melhorar a doação de órgãos na Espanha. Matesanz (MATESANZ, 2009; MATESANZ, 2014), por longo tempo diretor da Organización Nacional de Trasplantes (ONT) do país, apresentou três razões para o fato de a Espanha seguir liderando o ranking mundial: a solidariedade de seus cidadãos, o amplo e eficiente sistema nacional de saúde e a qualificação e o treinamento das equipes. Mesmo assim, o país deve continuar tendo em conta expectativas com o cultivo de órgãos e tecidos em laboratório a partir de células-tronco e com a criação de órgãos bioartificiais.

Os espanhóis - paradoxalmente - enfrentam um problema diante das boas cifras. O país teve que atentar para a ameaça do turismo de transplante: pessoas chegando do exterior e que tendem a procurar brechas na legislação nacional para acessar fraudulentamente as listas de espera. Em 2017, expôs-se o caso dos

(...) búlgaros ${ }^{9}$ que em 2015 viajaram para a Espanha com falsos contratos de trabalho para acesso à diálise e transplantes em Madrid, dentro do que a Guarda Civil denominou Operação Renibus, foi apenas a ponta do iceberg que nos permitiu detectar casos semelhantes entre diferentes nacionalidades em outros países. [...] A isto deve ser adicionado o risco real da população local se recusar a doar órgãos se eles acabarem principalmente em pacientes de fora do país e quase sempre com dinheiro [público] no meio. [...] Para impedir esse fenômeno crescente à medida que os países se destacam em transplantes, é estabelecer um período mínimo de residência para poder acessar as listas de espera. (MATESANZ, 2017, online, tradução nossa).

\footnotetext{
${ }^{9}$ Em 2015, 56 transplantes de rins realizaram-se na Bulgária e, em 2012, 19. (VILLARREAL, 2016).
} 
A OMS, o Conselho da Europa e o Conselho Ibero-americano de Doação e Transplante concordaram com a medida, disse Matesanz (MATESANZ, 2017). É a própria credibilidade futura do sistema a depender disso.

A Turquia aparece inicialmente, em 2010, como nona colocada, mas finaliza o período (2016) na sexta colocação, junto a Espanha e Reino Unido. De 2010 a 2011 , a Turquia ascendeu seus números absolutos em torno de $25 \%$, com ascensão média de $8 \%$. A segunda maior taxa de ascendência anual, perdendo apenas para Índia com 36\%, entre 2013 e 2014 (Figura 1). Nesse país, apenas o período entre 2013 e 2014 não houve crescimento nos números, fato que mostra um avanço sólido do tema em questão.

O governo turco investiu mais de 30.000 milhões de dólares em turismo sanitário nos últimos dez anos. Transplantes de cabelo, cirurgias estéticas, tratamentos oncológicos. O sistema, famoso também por transplantes de órgãos, havia ficado abalado depois de denúncias de compra e venda de órgãos no mercado negro. Em 2015, as autoridades turcas capturaram um israelense que aliciava refugiados sírios que seriam transplantados em cidades do país (MORAG, 2015). Mas as autoridades afirmam que há 15 anos o Ministério da Saúde controla o assunto e que transplantes de órgãos em pacientes estrangeiros somente são autorizados se estes trouxerem seu próprio doador, de origem familiar consanguínea até quarto grau; e uma junta médica deve estar convencida de que inexiste transação monetária envolvida. O Conselho Turco de Turismo Sanitário, criado em 2005, conta com 365 membros, dentre os quais hospitais, clínicas, agências de viagens e hotéis, e espera alcançar um milhão de pacientes em 2019 e dois milhões em 2023. Em 2016, foram mais de 750 mil pacientes, de 144 países, e que injetaram quase seis milhões de dólares na economia turca (ALONSO, 2018).

Concluindo o Top 10 do ranking dos países em números de transplantes, a Itália só consegue evoluir de forma concreta nos últimos três anos avaliados (2014, 2015 e 2016). De 2015 para 2016, essa ascensão chega a 12\%, número elevado para os padrões dos principais países europeus (Figura 1). Com essa alavancagem, a Itália 
ultrapassa os números da Alemanha, que vem regredindo seus indicadores desde 2010.

Fora do Top 10 mas parte desse processo analítico, tem-se a República da Coreia e o Irã. Com dados apresentados para os anos de 2010 a 2015, a República da Coreia e o Irã realizaram, cada um, em torno de 18.300 transplantes. Sendo que na Coreia, observa-se uma ascensão galopante entre os anos 2011-2012 de 31\%, perdendo apenas para valores obtidos na Índia, um país gigantesco. Com uma taxa média de crescimento de 8\%, a República da Coreia já chega ao top 10, em 2015, tirando a Itália do páreo (Figura 1). Já o Irã, cresce de forma relativamente contínua, com uma média de 5\% ao ano. Em 2016, esse país consegue números muitos próximos dos de Itália e Alemanha (Figura 1).

O Irã é o único país do mundo em que a venda de órgãos de pessoa viva é permitida. O programa atual data de 1988 e dele não podem participar estrangeiros. O paciente é encaminhado para uma associação que busca potenciais doadores. $\mathrm{O}$ governo paga pelas cirurgias e o doador recebe cobertura plena de saúde por um ano e uma redução no preço de seu plano de saúde nos hospitais públicos pelos anos seguintes. Os intermediários não são pagos. O doador recebe, em contrapartida, aproximadamente, 4.500 dólares de compensação financeira, a ser liberado depois da cirurgia. Colaboradores ricos ou instituições de caridade efetuam o pagamento para pacientes pobres que não têm como pagar pelo órgão. Os procedimentos cirúrgicos precisam ser aprovados pelo Departamento de Saúde do governo e só acontecem em hospitais credenciados e fiscalizados. No Irã, devedores podem ser condenados à prisão; e, portanto, a venda de rim surge como alternativa para endividados (KARIMI, 2016). Mas o arrependimento é alto: $79 \%$ dos iranianos que venderam um de seus rins lamentam a decisão (BURGOS, 2016).

Para uma análise quantitativa das informações apresentadas na Figura 1, a Tabela 1 apresenta as taxas de ascensão ou recessão dos países analisados durante o período 2010-2016. Esses números relacionados a políticas aplicadas nos diferentes países podem dar indícios de quais delas podem ser utilizadas para alavancar os números de doações e transplantes no globo. 
TABELA 1 - Taxas de ascensão/recessão no número de doações/transplantes entre 2010 e 2016.

\begin{tabular}{crrrrrrr}
\hline País & $\mathbf{2 0 1 0 - 2 0 1 1}$ & $\mathbf{2 0 1 1 - 2 0 1 2}$ & $\mathbf{2 0 1 2 - 2 0 1 3}$ & $\mathbf{2 0 1 3 - 2 0 1 4}$ & $\mathbf{2 0 1 4 - 2 0 1 5}$ & $\mathbf{2 0 1 5 - 2 0 1 6}$ & Média \\
\hline EUA & $6,70 \%$ & $-1,60 \%$ & $2,60 \%$ & $1,70 \%$ & $4,70 \%$ & $8,60 \%$ & $\mathbf{3 , 7 8 \%}$ \\
China & $0,00 \%$ & $0,00 \%$ & $0,00 \%$ & $0,00 \%$ & $27,90 \%$ & - & $\mathbf{5 , 5 8 \%}$ \\
Brasil & $9,40 \%$ & $8,20 \%$ & $3,70 \%$ & $0,90 \%$ & $1,00 \%$ & $2,50 \%$ & $\mathbf{4 , 2 7 \%}$ \\
Índia & $6,90 \%$ & $0,00 \%$ & $0,00 \%$ & $35,80 \%$ & $0,00 \%$ & - & $\mathbf{8 , 5 6 \%}$ \\
França & $6,60 \%$ & $1,50 \%$ & $2,00 \%$ & $4,50 \%$ & $7,10 \%$ & $2,60 \%$ & $\mathbf{4 , 1 0 \%}$ \\
Alemanha & $0,00 \%$ & $-7,70 \%$ & $-11,30 \%$ & $-4,90 \%$ & $-2,10 \%$ & $-2,00 \%$ & $\mathbf{- 4 , 6 0 \%}$ \\
Reino Unido & $9,70 \%$ & $4,90 \%$ & $12,70 \%$ & $2,00 \%$ & $0,90 \%$ & $2,60 \%$ & $\mathbf{4 , 5 0 \%}$ \\
Turquia & $24,50 \%$ & $0,80 \%$ & $7,30 \%$ & $-0,50 \%$ & $6,60 \%$ & $8,10 \%$ & $\mathbf{7 , 8 0 \%}$ \\
Espanha & $15,00 \%$ & $-1,10 \%$ & $1,90 \%$ & $1,80 \%$ & $9,40 \%$ & $0,90 \%$ & $\mathbf{4 , 7 0 \%}$ \\
Itália & $5,30 \%$ & $-1,00 \%$ & $-1,90 \%$ & $4,70 \%$ & $2,20 \%$ & $12,30 \%$ & $\mathbf{3 , 6 0 \%}$ \\
República da & $1,00 \%$ & $31,30 \%$ & $-1,30 \%$ & $3,80 \%$ & $7,60 \%$ & - & $\mathbf{8 , 5 0 \%}$ \\
Coreia & $4,90 \%$ & $10,70 \%$ & $11,80 \%$ & $-9,60 \%$ & $10,0 \%$ & $1,90 \%$ & $\mathbf{5 , 0 0 \%}$ \\
Irã &
\end{tabular}

Apesar dos números absolutos elevados dos EUA, sua taxa média é uma das

mais baixas entre os países analisados (3,78\%), estando à frente somente de Itália $(3,60 \%)$ e de Alemanha que possui média negativa $(-4,60 \%)$, pois em todo o período sofre recessão devido a escândalos ocorridos no sistema de doações e transplantes. Contudo, as taxas americanas, assim como as italianas, veem crescendo no decorrer dos últimos anos analisados. As taxas médias mais elevadas ocorrem na Índia (8,56\%), República da Coreia (8,50\%) e Turquia (7,80\%) devido a, em alguns momentos do período em análise, obtenção de taxas surpreendentemente elevadas.

No que se refere à obtenção de órgãos de doadores falecidos, os países em análise trabalham com um dos dois sistemas elencados pela OMS. O primeiro é o sistema de consentimento expresso (opting in / contracting in), segundo o qual o falecido manifestou expressamente antes de morrer a autorização para a extração; ou um familiar, para o caso de a pessoa não ter deixado nenhuma declaração. Dependendo da legislação nacional, esse consentimento poderá efetuar-se verbalmente ou ser registrado em um cartão de doador, na carteira nacional de habilitação, em documento de identidade, no histórico médico ou em um registro de doadores. O segundo é o sistema de consentimento presumido (opting out / contracting out) ou sistema de exclusão, por meio do qual pode-se extrair órgãos do corpo da pessoa falecida para fins de transplante, a menos que ela tenha manifestado em vida sua oposição ou que alguém declare que o falecido se opunha. 
Dos países estudados, Espanha e França adotam o sistema opt out, de presunção ou de exclusão, sendo que este último adaptou sua legislação recentemente. O Reino Unido estaria averiguando a possibilidade de alterar seu sistema opt in para opt out.

Enquanto isso, brasileiros, alemães e americanos são contrários ao sistema de consentimento presumido (opt out).

No Brasil, a decisão sobre a doação pertence aos familiares do potencial doador. Houve, com a Lei no 9.434 de 1997, uma tentativa de alteração para o sistema de consentimento presumido, em sentido diverso ao que era estabelecido pela Lei no 5.479 de 1968. Entretanto, diante da não aceitação por parcela expressiva da sociedade brasileira, o consentimento expresso voltou a ser exigido a partir de uma medida provisória convertida, depois, na Lei no 10.211 de 2001. Portanto, a retirada de órgãos e partes do corpo de pessoas falecidas para transplantes ou para outra finalidade terapêutica depende, no país, da autorização do cônjuge ou parente firmada em documento subscrito por duas testemunhas presentes à verificação da morte. Sempre que as doações intervivos envolverem doadores não aparentados, deverão ser submetidas, previamente à autorização judicial, à aprovação da Comissão de Ética do estabelecimento de saúde transplantador e da Central de Notificação, Captação e Distribuição de Órgãos - CNCDO, assim como comunicadas ao Ministério Público. ${ }^{10}$

A Alemanha também tentou, sem sucesso, por ao menos duas oportunidades, uma em 1978 e outra em 1997 (DEN BÜRGERN, 2018), adotar o sistema presumido. No país, a pessoa só se torna um doador se tiver optado explicitamente pelo sistema ao assinar um cartão de doador de órgãos (ORGAN SCANDAL, 2012). Mas, segundo uma legislação de 2012, as pessoas com mais de 16 anos de idade serão solicitadas pelo menos uma vez durante sua vida a decidir se querem doar (ORGAN TRANSPLANT, 2012; GERMAN, 2012). A lei vincula ainda empresas de seguro médico a informarem regularmente a seus clientes sobre a doação de órgãos (GERMANY, 2013).

${ }^{10}$ Consultar o Regulamento Técnico do Sistema Nacional de Transplante. 
Trata-se, aqui, dos chamados nudges, pequena "cutucada" de modo a incentivar a doação de órgãos, sugerida em trabalho de Cioatto e Alencar e assunto de uma edição especial da Revista de Políticas Públicas do PPGD da Uniceub, o volume 8, número 2, de 2018.

Alguns estados americanos como Connecticut, Texas, Colorado ${ }^{11} \mathrm{e}$ Pensilvânia ${ }^{12}$ consideraram alterar sua legislação, sem êxito. Os americanos, resistentes ao sistema presumido, insinuam que, após a morte, os corpos passariam a ser propriedade do Estado - com o que não podem concordar. Embora bemintencionada, a adoção deste sistema poderia reduzir e não aumentar o número de doações nos Estados Unidos exatamente por serem os americanos contrários ao controle do Estado sobre seus corpos, contrários à ideia de um governo tomando decisão por eles. Os direitos individuais, no país, são muito importantes (SAMUEL, 2017).

Dos mais de 50 estados americanos, em Illinois existe a chamada "escolha obrigatória”, e sob a qual as pessoas devem indicar sua preferência. Desde 2006, quando o cidadão vai renovar sua carteira de motorista e atualizar sua fotografia, é obrigado a responder se deseja ser um doador de órgãos, o que teria elevado significativamente a taxa de doadores. O sistema, aqui, vincula juridicamente os desejos da pessoa de ser doador, independente da vontade ou da oposição de familiares (THALER, 2009). ${ }^{13}$

Para Benjamin (2016), a comunicação oficial sobre a doação de órgãos deve ser adequada. Deve-se claramente informar sobre o suposto consentimento e o direito de recusar. A lei não deve surgir como expressão de uma política agressiva, correndo o risco de ter o efeito oposto. A colheita de órgãos deve sempre aparecer como expressão altruísta, um ato de generosidade após a morte.

11 <http://www.leg.state.co.us/clics/clics2011a/csl.nsf/billcontainers/319B3F36D587959D8725780100604 99C/\%24FILE/042_01.pdf>. Acesso em: 24 mar. 2018.

12 Projeto disponível em: <http://www.legis.state.pa.us/CFDOCS/Legis/PN/Public/btCheck.cfm?txtType=PDF\&sessYr=2013\&se sslnd=0\&billBody=S\&billTyp=B\&billNbr=1306\&pn=1876>. Acesso em: 24 mar. 2018.

13 Disponível em: <http://www.donatelifeillinois.org/>. 
Uma política que deve ser adotada é a constante capacitação e a sensibilização das equipes de captação, médicos, enfermeiros, psicólogos, que podem ajudar a reduzir os medos de muitos pacientes e parentes e a fortalecer a confiança na medicina de transplante. A Espanha é um dos países que usam esse tipo de estratégia e ganha muitos adeptos devido à relação de confiança existente entre a comunidade espanhola e o sistema de doações e transplantes.

Análises sobre a redução de descartes e a reformulação das prioridades nas listas de receptores também são avaliadas em alguns países. Em 2011, 2.644 dos 14.784 rins extraídos nos Estados Unidos foram descartados. E o número de descartes cresceu $76 \%$ na década. Mais da metade dos rins descartados vinham de doadores mais velhos, cuja idade e problemas de saúde podem tê-los marginalizado para transplante. Mas a outra metade era de doadores com menos de 60 anos. Entretanto, acredita-se que uma quantidade significativa de rins descartados pudesse ser transplantada se o sistema combinasse melhor o órgão com o destinatário. Tal seria possível caso o sistema de correspondência renal considerasse a expectativa de vida projetada do receptor ou a urgência do transplante, como acontece com os sistemas para alocação de fígados, corações e pulmões (SACK, 2014). Poder-se-ia organizar as listas de modo a combinar as pessoas para maximizar o resultado de cada rim. Por exemplo, não repassando um rim que pode durar 40 anos para alguém que é esperado viver mais cinco. Dentre as mudanças propostas encontrar-se-ia a seguinte: os $20 \%$ dos rins que seriam esperados para durar mais tempo iriam para os $20 \%$ de receptores esperados para obter o maior número de anos de cada órgão. Como resultado, muito mais anos de vida vividos com cada transplante de rim. Como consequência, como essas pessoas viveriam mais, diminuir-se-ia o número de doentes com insuficiência renal que precisam retornar à lista de espera (STEIN, 2012). A renovação do sistema de alocação evitaria que rins que podem funcionar por muitos anos fossem encaminhados para pacientes idosos com pouca expectativa de vida e que rins de menor qualidade não fossem recusados por médicos a esperar por órgãos 
melhores. ${ }^{14}$ Uma classificação de cada rim com base na idade, altura, peso e histórico médico do doador foi uma sugestão apresentada: os primeiros $20 \%$ seriam alocados a receptores com maior expectativa de vida. Ocorre que o uso da idade para determinar o transplante foi considerado discriminatório pelos americanos. Inobstante, europeus, dentre estes alemães, combinam rins de doadores com 65 anos ou mais para receptores na mesma faixa etária. E esses órgãos foram alocados perto da casa do transplantado, para encurtar o tempo de isquemia. O número de doadores mais velhos teria mais que triplicado, a taxa de descarte seria um terço menor que a dos Estados Unidos e não teriam sido encontradas diferenças significativas nas taxas de sobrevivência dos pacientes idosos entre os dois países (SACK, 2014). O "debate sobre os transplantes de rins é um prenúncio para outros debates semelhantes que estão chegando à medida que a população envelhece e a pressão para restringir os custos se intensifica." (STEIN, 2012, online, tradução nossa).

Além disso, reduzir as exigências para órgãos doados, como ampliar a aceitação de órgãos de qualidade questionável, de doadores muito idosos, com 70, 80, 90 anos de idade (ALECCIA, 2016), e de órgãos que vêm de doadores com comportamentos de risco, tal qual o uso de drogas. Mais de $50 \%$ dos doadores em Espanha têm de 60 anos, existindo registro de pessoas que doaram seu fígado depois de morrer com mais de 90 anos de idade (IRIBERRI, 2017). Ainda, que pacientes não infectados pudessem consentir em receber doações de pessoas que carregam patógenos como hepatite C ou HIV (TRUOG, 2017) são sugestões cogitadas.

A distância entre os pacientes e o centro de transplante também ainda é um empecilho, visto que o tempo de duração do órgão não é muito. Aproximá-los ou preservar os órgãos doados por mais tempo está entre as metas. Novas técnicas poderiam prolongar o tempo de duração de um órgão fora do corpo.

Claramente, há uma forte necessidade de abordagens inovadoras para o problema. Cientistas estão trabalhando em uma técnica chamada xenotransplante ou cultivo de órgãos em outros animais - como porcos - que poderiam ser viáveis em

\footnotetext{
${ }^{14}$ Dentre as razões pelas quais um médico afasta um rim, há a pressão para manter altas taxas de sucesso de transplantes; do contrário, o programa, nos Estados Unidos, é descredenciado.
} 
humanos (BEGLEY, 2017). Outros pesquisadores estão tentando criar órgãos artificiais que possam ser cultivados em laboratório.

\begin{abstract}
É aqui que a revolução das células-tronco dos últimos 10 anos oferece uma medida de esperança. Para entender os desafios no crescimento de um rim a partir de células-tronco, é útil comparar as abordagens de células-tronco para insuficiência renal com aqueles para diabetes. Pacientes com diabetes tipo 1 sofrem com o fracasso de um único tipo de célula no pâncreas, chamado de célula beta. Nos últimos 10 anos, os cientistas conseguiram gerar células beta no laboratório - bilhões delas - e agora o único desafio que resta para curar o diabetes tipo 1 é encontrar uma maneira de entregar essas células a um paciente e mantê-las vivas. A insuficiência renal, por outro lado, representa a falha de um órgão inteiro composto por mais de 30 tipos de células distintas, todas organizadas em um padrão intrincado e complicado. O desafio não é apenas cultivar 30 tipos de células diferentes, mas também como organizá-las na orientação apropriada. Até dois anos atrás, as perspectivas de superação desses desafios pareciam escassas, apesar de décadas de esforços de grandes equipes de cientistas em todo o mundo. (HUMPHREYS, 2018, online, tradução nossa).
\end{abstract}

Obviamente, vários desafios substanciais permanecem.

\title{
CONCLUSÃO
}

O número de órgãos doados e disponíveis para transplantação são pouco expressivos se considerada a demanda por transplantes. Mesmo os países com os melhores números de doações e transplantes, pessoas morrem por falta de órgãos.

Como uma primeira medida para aumentar a quantidade ofertada, geralmente cogita-se a adoção do sistema presumido de doação, que deve ser acompanhado de claras e amplas informações sobre a presunção do consentimento e sobre o direito de recusar. Caso a população não seja esclarecida de forma adequada, o efeito da política pode ser contrário.

Em seguida, há uma necessidade reconhecida de treinarem-se extensivamente todos os envolvidos no processo, e tornarem-se mais instruídas sobre doação as pessoas. Despertar o altruísmo e a generosidade, incentivar as constantes 
conversas familiares sobre o tema. Mais do que o vínculo jurídico, estas parecem ser chaves para o sucesso dos programas de doação de órgãos de falecidos.

Considerando os riscos inerentes aos doadores vivos, que envolvem todo $\mathrm{e}$ qualquer procedimento cirúrgico, as doações de pessoas falecidas devem ser desenvolvidas até o máximo potencial terapêutico.

Considerar o critério de morte cardiocirculatória para a extração de órgãos, e não exclusivamente o de morte encefálica, é uma das alterações a ser considerada. Países que usam esse procedimento como fonte de doações possuem números elevados e/ou taxas anuais de doações em ascendência.

Quanto ao programa de doação intervivos, a necessidade de ofertar incentivos torna-se cada vez mais coerente, como reembolsar as perdas razoáveis e verificáveis em que incorrem os doadores, tais como o ingresso de rendimentos ou o pagamento de despesas. Assegurar-Ihes assistência médica vitalícia de qualidade, dar status preferencial nas listas de espera de transplante para doadores efetivos e para quem consentiu na doação de um parente são alternativas.

Exames e diagnósticos corretos em seus estágios iniciais de modo a atrasar e impedir que muito mais pessoas precisem de órgãos é fundamental.

Vários desafios permanecem, havendo uma forte necessidade de abordagens inovadoras para o problema de modo a garantir o direito constitucional à saúde àqueles que necessitam de um transplante.

\section{REFERÊNCIAS}

A PARTIR DU 1er janvier, tous les Français seront donneurs d'organes par défaut. Lexpress, 29 dec. 2016.2 Disponível em: $<$ https://www.lexpress.fr/actualite/societe/sante/a-partir-du-1er-janvier-tous-lesfrancais-seront-donneurs-d-organes-pardefaut_1864325.html?utm_campaign=Echobox\&utm_medium=Social\&utm_source= Facebook\&link_time=1483015812\#xtor=CS3-5076>. Acesso em: 2018.

ALECCIA, JoNel. Senior Citizens, Even 80-Year-Olds, Can Be Organ Donors. KHN, 15 dec. 2016. Disponível em: <https://khn.org/news/senior-citizens-even-80-yearolds-can-be-organ-donors/>. Acesso em: 24 mar. 2018. 
ALONSO, Patricia. Turquía recupera el turismo con implantes de pelo y riñones a 35.000 dólares. El Español, 23 mar. 2018. Disponível em: $<$ https://www.elespanol.com/mundo/asia/20180323/turquia-recupera-turismoimplantes-pelo-rinones-dolares/293971739_0.html>. Acesso em: 01 abr. 2018.

ÄRZTE verlieren Vertrauen in Organspende. Spiegel Online, 26 may 2014. Disponível em: <http://www.spiegel.de/gesundheit/diagnose/transplantationen-aerzte-verlierenvertrauen-in-organspende-a-971573.html>. Acesso em: 27 mar. 2018.

BARROS, A.J.P., LEHFELD, N.A.S. Projeto de pesquisa: propostas metodológicas. $12^{\mathrm{a}}$ ed. Petrópolis, RJ: Vozes, 1990. 123p.

BARTENS, Werner; MAYER, Verena. Mitten ins Herz. Sueddeutsche Zeitung, 22 ago. $2014 . \quad$ Disponível em: $<$ http://www.sueddeutsche.de/gesundheit/manipulationsverdacht-am-herzzentrumberlin-mitten-ins-herz-1.2100176>. Acesso em: 6 mai. 2017.

BEGLEY, Sharon. She's hellbent on solving the organ shortage with 'designer pigs.' Just don't keep her waiting. Stat News, 6 apr. 2017. Disponível em: $<$ https://www.statnews.com/2017/04/06/crispr-pig-organs-transplant-luhan-yang/>. Acesso em: 24 mar. 2018.

BENJAMIN, Anna. Don d'organe: "Les prélèvements ne seront pas automatiques". Lexpress, $\quad 30 \quad$ dec. $2016 . \quad$ Disponível em: $<$ https://www.lexpress.fr/actualite/societe/sante/don-d-organe-les-prelevements-neseront-pas-automatiques_1864548.html >. Acesso em: 2018.

BERLIN DOCTOR accused of queue-jumping in heart transplants. DW, 22 ago. 2014. Disponível em: <http://www.dw.com/en/berlin-doctor-accused-of-queue-jumping-inheart-transplants/a-17872414>. Acesso em: 10 fev. 2018.

BERNDT, Christina. Falsche Angaben für Spenderlungen? Sueddeutsche Zeitung, 15 nov. 2016a. Disponível em: <http://www.sueddeutsche.de/gesundheit/organtransplantationen-falsche-angabenfuer-spenderlungen-1.3250738>. Acesso em: 6 mai. 2017.

. Manipulationen bei der Vergabe begehrter Spenderorgane. Sueddeutsche Zeitung, $\quad 6 \quad$ dez. $\quad 2016 \mathrm{~b}$. Disponível em: $<$ http://www.sueddeutsche.de/gesundheit/organspenden-manipulationen-bei-dervergabe-begehrter-spenderorgane-1.3282639>. Acesso em: 6 mai. 2017.

. Skandal um Herztransplantationen weitet sich aus. Sueddeutsche Zeitung, 15 out. 2015. Disponível em: <http://www.sueddeutsche.de/gesundheit/-skandal-umherztransplantationen-weitet-sich-aus-1.2694599>. Acesso em: 6 mai. 2017. 
$\begin{array}{cccc} & \text { Verfahren gegen Ärzte im Klinikum Großhadern eingestellt. Sueddeutsche } \\ \text { Zeitung, } & 31 & \text { mar. } 2017 . \quad \text { Disponível }\end{array}$ $<$ http://www.sueddeutsche.de/muenchen/transplantationen-verfahren-gegen-aerzteim-klinikum-grosshadern-eingestellt-1.3443818>. Acesso em: 6 mai. 2017.

BGH bestätigt Freispruch für Göttinger Transplantationsmediziner. Süddeutsche Zeitung, Munique, 28 juni 2017. Disponível em: $<$ http://www.sueddeutsche.de/gesundheit/transplantationsskandal-bgh-bestaetigtfreispruch-fuer-goettinger-transplantationsmediziner-1.3565423>. Acesso em: 27 mar. 2018.

BOYTCHEV, Hristio. Ethikrat streitet über Definition des Todes. Spiegel Online, 24 feb. 2015. Disponível em: <http://www.spiegel.de/gesundheit/diagnose/hirntod-undorganspende-ethikrat-streitet-ueber-definition-a-1019985.html>. Acesso em: 29 mar. 2018.

BRASIL. Constituição $\quad$ Federal. Disponível em: <http://www.planalto.gov.br/ccivil_03/constituicao/ConstituicaoCompilado.htm>. Acesso em: 17 jul. 2018.

Decreto no 9.175, de 18 de outubro 2017. Regulamenta a Lei no 9.434, de 4 de fevereiro de 1997, para tratar da disposição de órgãos, tecidos, células e partes do corpo humano para fins de transplante e tratamento. Revoga o Decreto oㅜ 2.268 de 30 de junho de 1997. Disponível em: <http://www.planalto.gov.br/ccivil_03/_Ato2015-

2018/2017/Decreto/D9175.htm\#art56>. Acesso em: 11 de nov. de 2017.

Lei no 5.479 de 10 de agosto de 1968. Disponível em: <http://www.planalto.gov.br/ccivil_03/leis/1950-1969/L5479.htm>. Acesso em: 11 de nov. de 2017. [Revogada pela Lei no 8.489 , de 1992]

Lei no 9.434 de 4 de fevereiro de 1997. Dispõe sobre a remoção de órgãos, tecidos e partes do corpo humano para fins de transplante e tratamento e dá outras providências.

Disponível

em: <http://www.planalto.gov.br/ccivil_03/leis/L9434compilado.htm>. Acesso em: 11 de nov. de 2017.

. MINISTÉRIO DA SAÚDE. Portaria no 2.600, de 21 de outubro de 2009. Aprova o Regulamento Técnico do Sistema Nacional de Transplantes. Disponível em: <http://bvsms.saude.gov.br/bvs/saudelegis/gm/2009/prt2600_21_10_2009.html>. Acesso em: 13 abr. 2018. 
BURGOS, Pedro. E se venda de órgãos fosse legalizada? Super Interessante, 31 out. 2016. Disponível em: <https://super.abril.com.br/saude/e-se-venda-de-orgaosfosse-legalizada/>. Acesso em: 30 mar. 2018.

CHINA to cease prisoner organ transplants. DW, 04 dez. 2014. Disponível em: $<$ http://www.dw.com/en/china-to-cease-prisoner-organ-transplants/a-18109346>. Acesso em: 10 fev. 2018.

CIOATTO, Roberta Marina; PINHEIRO, Adriana de Alencar Gomes. Nudges como Política Pública para aumentar o Escasso Número de Doadores de Órgãos para Transplante. Revista Brasileira de Políticas Públicas, v. 8, n. 2, 2018, p. Disponível em: <>. Acesso em:

$D E N$ BÜRGERN reinen Wein einschenken. Süddeutsche Zeitung, Munique, 6 märz. 2018. Disponível em: <http://www.sueddeutsche.de/kolumne/organspende-denbuergern-reinen-wein-einschenken-1.3894155>. Acesso em: 27 mar. 2018.

DIE AUFARBEITUNG der Altfälle geht ziemlich schleppend voran. Süddeutsche Zeitung, 15 nov. $2016 . \quad$ Disponível em: $<$ http://www.sueddeutsche.de/gesundheit/organtransplantationen-falsche-angabenfuer-spenderlungen-1.3250738-2>. Acesso em: 6 mai. 2017.

EL ÉXITO de los trasplantes. El País, 12 ene. 2018. Disponível em: <https://elpais.com/elpais/2018/01/12/opinion/1515782432_390027.html?id_externo_ rsoc=TW_CC\&utm_content=buffer2c070\&utm_medium =social\&utm_source=faceboo k.com\&utm_campaign=buffer $>$. Acesso em: 10 fev. 2018.

ESPANHA é campeã do mundo em doações de órgãos. Exame, 17 abr. 2017. Disponível em: <https://exame.abril.com.br/ciencia/espanha-e-campea-do-mundoem-doacoes-de-orgaos/>. Acesso em: 13 nov. 2017.

FAN, Jiayang. Can China Stop Organ Trafficking? The New Yorker, 10 jan. 2014. Disponível em: <http://www.newyorker.com/news/news-desk/can-china-stop-organtrafficking >. Acesso em: 01 mai. 2017.

GARRAFA, Volnei. O Mercado de Estruturas Humanas. Revista Bioética, v. 1, n. 2, 1993.

Disponível

em: <http://revistabioetica.cfm.org.br/index.php/revista_bioetica/article/view/490>. Acesso em: 13 abr. 2018.

GERMAN patients turn to Croatia for organ donations. DW, 29 jan. 2018. Disponível em: <http://www.dw.com/en/german-patients-turn-to-croatia-for-organ-donations/a42357468>. Acesso em: 24 mar. 2018. 
GERMAN parliament approves organ donation reform. DW, 25 may 2012. Disponível em: <http://www.dw.com/en/german-parliament-approves-organ-donation-reform/a15976888>. Acesso em: 25 mar. 2018.

GERMANY lags behind in organ donations. DW, 4 jan. 2013. Disponível em: $<$ http://www.dw.com/en/germany-lags-behind-in-organ-donations/a-16498057>. Acesso em: 24 mar. 2018.

GINZEL, Arndt; KRAUSHAAR, Martin; WINTER, Steffen. Desperation, Greed and the Global Organ Trade. Spiegel Online, 3 aug. 2012. Disponível em: $<$ http://www.spiegel.de/international/world/the-illegal-trade-in-organ-is-fueled-bydesperation-and-growing-a-847473.html>. Acesso em: 29 mar. 2018.

GLOBAL Observatory on Donation and Transplantation. World Health Organization (WHO). Disponível em: <http://www.transplant-observatory.org/summary/>. Acesso em: 10 nov. 2017.

HEINE, Hannes. Manipulation bei Organvergabe in Berlin? Der Tagesspiegel, 21 ago. 2014. Disponível em: <https://www.tagesspiegel.de/berlin/deutsches-herzzentrummanipulation-bei-organvergabe-in-berlin/10365692.html>. Acesso em: 27 mar. 2018. HUMPHREYS, Benjamin. Will lab-grown kidneys fix our transplant waiting lists? The Washington Post, 31 dec. 2018. Disponível em: $<$ https://www.washingtonpost.com/news/in-theory/wp/2015/12/31/will-lab-grownkidneys-fix-our-transplant-waiting-lists/?utm_term $=.80 \mathrm{a} 48 \mathrm{a} 10 \mathrm{db} 5 \mathrm{f}>$. Acesso em: 07 abr. 2018.

IRIBERRI, Ainhoa. Así prepararon durante cinco horas a Palomo Linares para poder trasplantar sus órganos. El Español, 25 abr. 2017. Disponível em: $<$ https://www.elespanol.com/ciencia/salud/20170424/210979467_0.html>. Acesso em: 07 abr. 2018.

KARIMI, Nasser; GAMBRELL, Jon. No Irã, sistema permite pagar abertamente a doadores de rim. Folha de São Paulo, São Paulo, 26 ago 2016. Disponível em: <http://www1.folha.uol.com.br/mundo/2016/08/1807507-no-ira-sistema-permitepagar-abertamente-a-doadores-de-rim.shtml>. Acesso em: 24 nov. 2017.

KIDNEYS on special offer. DW, 31 jul. 2012. Disponível em: <http://www.dw.com/en/kidneys-on-special-offer/a-16134667>. Acesso em: 25 mar. 2018.

MATESANZ, Rafael. El modelo español de donación y trasplante. Análisis Madri+d. 23 set. 2009.2 Disponível em: <http://www.madrimasd.org/informacionldi/analisis/analisis/analisis.asp?id=39863>. Acesso em: 15 nov. 2017. 
MATESANZ, Rafael. Entrevista: El Milagro de los Trasplantes. Instituto Thomás Pascual Sanz. $2014 . \quad$ Disponível em: <https://www.youtube.com/watch?v=X0DOH2xUWbw>. Acesso em: 15 nov. 2017.

MATESANZ, Rafael. The threat of transplant tourism. Agência Efe, 26 Sep. 2017. Disponível em: <https://www.efe.com/efe/english/efe-opinion-makers/the-threat-oftransplant-tourism/50001053-3390795>. Acesso em: 30 mar. 2018.

MORAG, Gilad. Turkish authorities arrest Israeli suspected of organ trafficking. YnetNews, 12 may 2015.2 Disponível em: <https://www.ynetnews.com/articles/0,7340,L-4735121,00.html>. Acesso em: 27 mar. 2018.

NEW DUTCH law makes every adult an organ donor. DW, 14 feb. 2018. Disponível

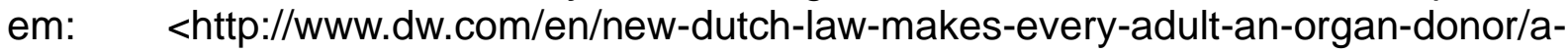
42576784>. Acesso em: 24 mar. 2018.

ORGAN SCANDAL forces rethink of donor system. DW, 6 ago. 2012. Disponível em: $<$ http://www.dw.com/en/organ-scandal-forces-rethink-of-donor-system/a-16146350>. Acesso em: 24 mar. 2018.

ORGAN TRANSPLANT transplant scandal shocks Germany. DW, 21 jul. 2012. Disponível em: <http://www.dw.com/en/organ-transplant-scandal-shocks-germany/a16116631>. Acesso em: 25 mar. 2018.

ORGANIZAÇÃO MUNDIAL DA SAÚDE - OMS. WHA 63/22. Princípios Orientadores da OMS sobre transplante de células, tecidos y órgãos humanos aprovados pela $63^{\text {a }}$ Assembleia Mundial de Saúde, de maio de 2010. Disponível em: $<$ http://www.who.int/transplantation/Guiding_PrinciplesTransplantation_WHA63.22sp. pdf?ua=1>. Acesso em: 12 nov. 2017.

OSSOLA, Alexandra. Crisis in America: Medical experts use new tech tools to combat the organ transplant shortage. CNBC, 21 jun. 2017. Disponível em: <https://www.cnbc.com/2017/06/20/medical-experts-use-new-tech-tools-to-combatorgan-transplant-shortage.html>. Acesso em: 24 mar. 2018.

RTB - Registro Brasileiro de Transplantes. ABTO - Associação Brasileira de Transplante de Órgãos. São Paulo, ano XXIII, oㅡ 4, jan./dez. 2017. Disponível em: $<$ http://www.abto.org.br/abtov03/default.aspx? $\mathrm{mn}=515 \& \mathrm{c}=900 \& \mathrm{~s}=0$ \&friendly=registro -brasileiro-de-transplantes-estatistica-de-transplantes>. Acesso em: 07 nov. 2017.

SACK, Kevin. A Clash of Religion and Bioethics Complicates Organ Donation in Israel. The New York Times, 17 aug. 2014. Disponível em: $<$ https://www.nytimes.com/2014/08/17/world/middleeast/a-clash-of-religion-andbioethics-complicates-organ-donation-in-israel.html>. Acesso em: 04 abr. 2018. 
SAMUEL, Leah. To solve organ shortage, states consider 'opt-out' organ donation laws. Stat News, 6 jul. 2017. Disponível em: <https://www.statnews.com/2017/07/06/optsolution-organ-shortage/>. Acesso em: 24 mar. 2018.

SELBSTANZEIGE für die Transparenz. Süddeutsche Zeitung, Munique, 22 ago. 2014.

$<$ http://www.sueddeutsche.de/gesundheit/manipulationsverdacht-am-herzzentrumberlin-mitten-ins-herz-1.2100176-2>. Acesso em: 27 mar. 2018.

STEIN, Rob. Who's Next In Line For A Kidney Transplant? The Answer Is Changing. NPR, 20 sep. 2012. Disponível em: <https://www.npr.org/sections/healthshots/2012/09/20/161475405/whos-next-in-line-for-a-transplant-the-answer-ischanging >. Acesso em: 29 mar. 2018.

THALER, Richard H. Opting in vs. Opting Out. The New York Times, 26 sep. 2009. Disponível em: <https://www.nytimes.com/2009/09/27/business/economy/27view.html>. Acesso em: 24 mar. 2018.

TRUOG, Robert; SEGAL, Brad. Options for Increasing the Supply of Transplantable Organs. Harvard Health Policy Review, 2 dec. 2017. Disponível em: $<$ http://bioethics.hms.harvard.edu/news/ethical-constraints-organ-rationing >. Acesso em: 24 mar. 2018.

VATICAN CONFERENCE challenges China on organ transplant ethics. DW, 08 fev. 2017. Disponível em: <http://www.dw.com/en/vatican-conference-challenges-chinaon-organ-transplant-ethics/a-37451147>. Acesso em: 10 fev. 2018.

VILLARREAL, Antonio. ¿Por qué hay búlgaros buscando un trasplante de riñón en España? El Español, 12 abr. 2016. Disponível em: <https://www.elespanol.com/ciencia/salud/20160411/116488607_0.html>. Acesso em: 30 mar. 2018.

YANG, Ying. Death row inmates number one organ donors in China. DW, 9 mar. 2012. Disponível em: <http://www.dw.com/en/death-row-inmates-number-one-organdonors-in-china/a-15800312>. Acesso em: 25 mar. 2018.

WER NICHT widerspricht, wird Organspender. Süddeutsche Zeitung, Munique, 13 feb. 2018. Disponível em: <http://www.sueddeutsche.de/politik/niederlande-wer-nichtwiderspricht-wird-organspender-1.3866596>. Acesso em: 27 mar. 2018.

WIDMAN, Miriam. Germans Willing to Donate Organs, But Often Don't. Spiegel Online, 22 jun. 2012. Disponível em: $<$ http://www.spiegel.de/international/germany/new-german-law-aims-to-increaseorgan-donation-a-840003.html>. Acesso em: 29 mar. 2018. 